\title{
Mucormycosis causing giant gastric ulcers
}

A 53-year-old woman with known ulcerative colitis, who had previously taken oral prednisolone on occasions for intermittent diarrhea, was admitted with urosepsis due to Escherichia coli that required treatment with inotropic agents and intravenous steroids. She was passing melena and was anemic with a hemoglobin of $6.2 \mathrm{~g} / \mathrm{dL}$, which failed to improve despite the transfusion of large volumes of blood and the administration of intravenous pantoprazole. Gastroscopy revealed multiple large superficial plaque-like ulcers in the upper and mid stomach with overlying slough ( $\bullet$ Fig. 1).

Specimens taken from the ulcer edge examined histologically revealed chronic active gastritis with cryptitis, crypt abscesses, and a noncaseating granuloma, but no evidence of malignancy ( $\bullet$ Fig. 2 a).

Typical fungal hyphae of a zygomycete, characteristic of mucormycosis, were seen on staining with hematoxylin and eosin ( Fig. 2b), and candidal yeasts were seen on staining with Grocott's methenamine silver ( $\bullet$ Fig. 3 ).

Standard culture was negative for mucormycosis. No evidence of dissemination was noted on computed tomography (CT). She was treated with intravenous amphotericin B for 4 weeks, and a repeat endoscopy 8 weeks later revealed scarring, biopsies of which were negative for fungi.

Mucormycosis is a rare fungal infection and an important cause of morbidity and mortality in immunocompromised patients. Common predisposing factors include diabetes, lymphoma, leukemia, renal disease, septicemia, malnutrition, and treatment with immunosuppressants [1 -3]. In a meta-analysis of 929 cases, 66

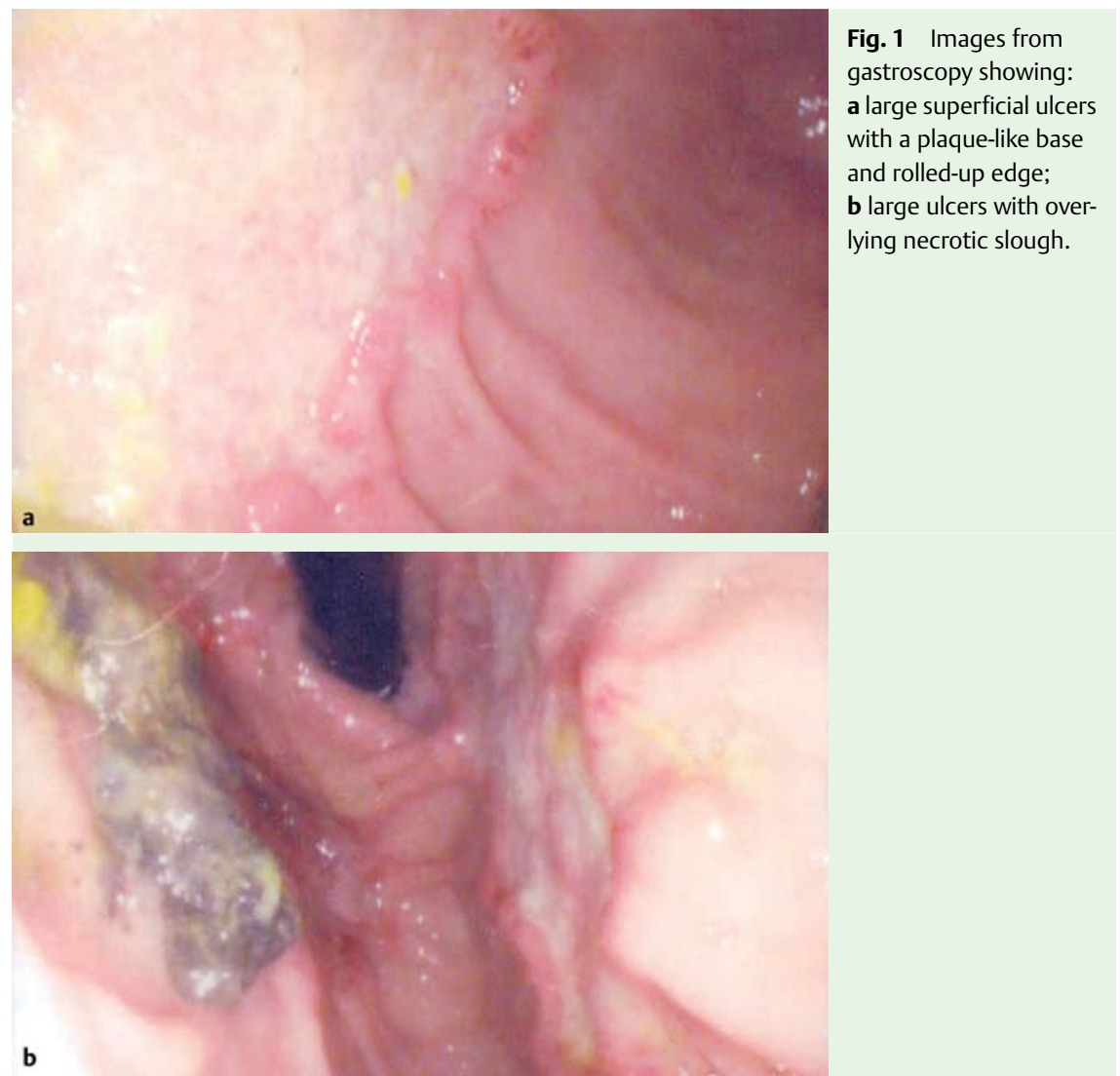

patients (7\%) had gastrointestinal infection [2]. Although uncommon, reported manifestations of gastrointestinal mucormycosis range from colonization of peptic ulcers to infiltrative disease [1]. All portions of the alimentary tract are vulnerable, with the stomach being the commonest site of infection [4]. The mortality is high in patients with invasive disease [5]. Treatment is usually with intravenous amphotericin B or oral posaconazole; however, surgical intervention should be considered for uncontrollable gastrointestinal hemorrhage or perforation.

Gastrointestinal mucormycosis is rare, but should be considered at endoscopy if an atypical ulcer is identified. In this case, the infection may have developed secondarily to immunosuppression.

Endoscopy_UCTN_Code_CCL_1AB_2AD_3AC

Competing interests: None 

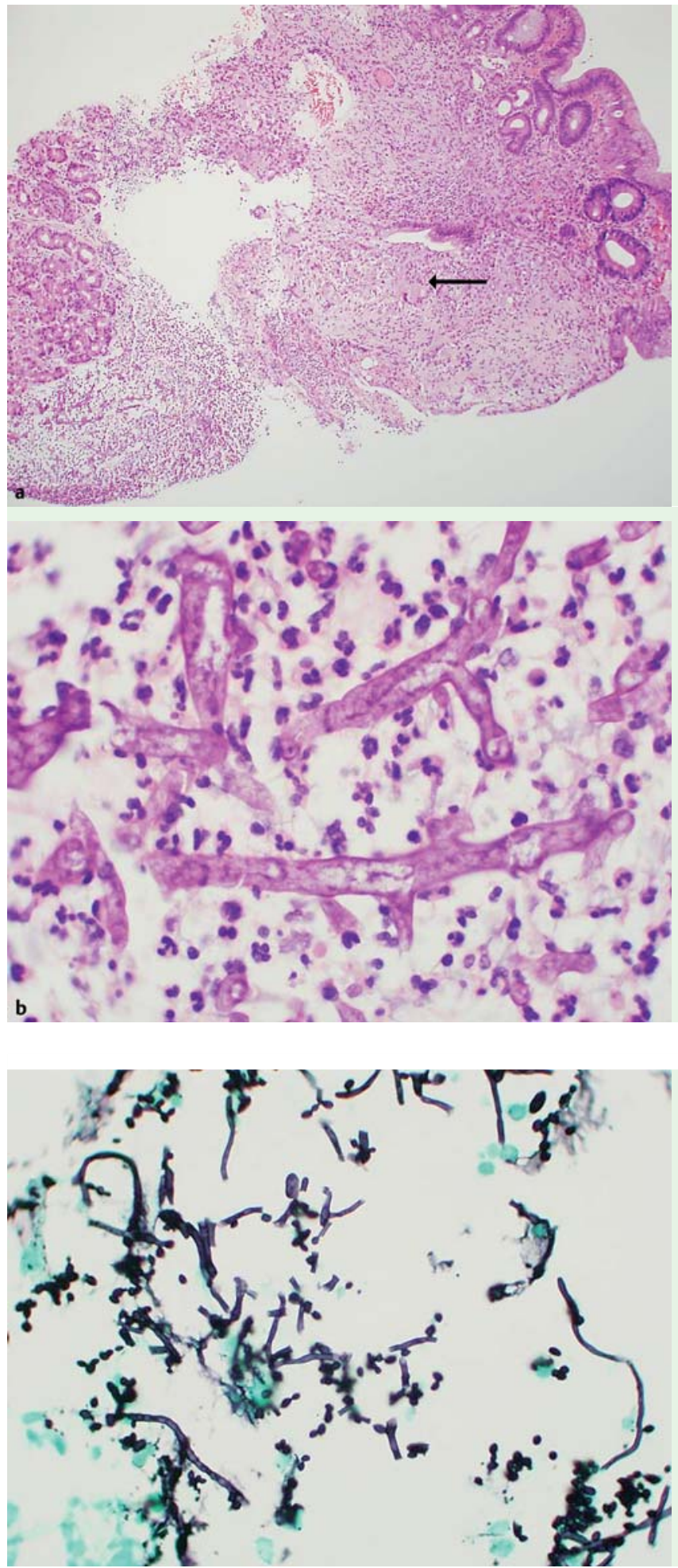

Fig. 2 Biopsy taken from the edge of an ulcer stained with hematoxylin and eosin (H\&E) showing: a chronic active gastritis and a noncaseating granuloma (arrow), b broad, irregular, nonseptate, branching hyphae typical of mucormycosis.

Fig. 3 Biopsy taken from the edge of an ulcer stained with Grocott's methenamine silver showing budding yeast forms typical of candida.
V. Chhaya, S. Gupta, A. Arnaout

Department of Gastroenterology, Croydon University Hospital, England

\section{References}

1 Lehrer RI, Howard DH, Sypherd PS et al. Mucormycosis. Ann Intern Med 1980; 93: 93 108

2 Roden MM, Zaoutis TE, Buchanan WL et al. Epidemiology and outcome of zygomycoses: a review of 929 reported cases. Clin Infect Dis 2005; 41: 634-653

3 Dannheimer IP, Fouvhe W, Nel C. Gastric mucormycosis in a diabetic patient. S Afr Med J 1974; 48: 838-839

4 Agha FP, Lee HH, Boland CR et al. Mucormycoma of the colon: early diagnosis and successful management. AJR Am J Roentgenol 1985; 145: 739

5 Cherney CL, Chutuape A, Fikrig MK. Fatal invasive gastric mucormycosis occurring with emphysematous gastritis: case report and literature review. Am J Gastroenterol 1999; 94: 252

\section{Bibliography}

DOI $10.1055 / \mathrm{s}-0030-1256425$

Endoscopy 2011; 43: E289-E290

(c) Georg Thieme Verlag KG Stuttgart · New York . ISSN 0013-726X

Corresponding author

V. Chhaya, MB, BS, MRCP, B.Sc.

Department of Gastroenterology

Croydon University Hospital

530 London Road

Croydon

CR7 7YE

United Kingdom

Fax: +44-20-84013495

vivek.chhaya@mayday.nhs.uk 